\title{
Biosorption characteristics of uranium(VI) from aqueous solution by pummelo peel
}

\author{
Qin Li $\cdot$ Yunhai Liu $\cdot$ Xiaohong Cao • \\ Cui Pang $\cdot$ Youqun Wang $\cdot$ Zhibin Zhang \\ Yating Liu $\cdot$ Ming Hua
}

Received: 21 November 2011/Published online: 10 March 2012

(C) Akadémiai Kiadó, Budapest, Hungary 2012

\begin{abstract}
The biomass pummelo peel was chosen as a biosorbent for removal of uranium(VI) from aqueous solution. The feasibility of adsorption of U(VI) by Pummelo peel was studied with batch adsorption experiments. The effects of contact time, biosorbent dosage and $\mathrm{pH}$ on adsorption capacity were investigated in detail. The pummelo peel exhibited the highest $\mathrm{U}(\mathrm{VI})$ sorption capacity $270.71 \mathrm{mg} / \mathrm{g}$ at an initial $\mathrm{pH}$ of 5.5 , concentration of $50 \mu \mathrm{g} /$ $\mathrm{mL}$, temperature $303 \mathrm{~K}$ and contacting time $7 \mathrm{~h}$. The adsorption process of $\mathrm{U}(\mathrm{VI})$ was found to follow the pseudo-second-order kinetic equation. The adsorption isotherm study indicated that it followed both the Langmuir adsorption isotherm and the Freundlich adsorption isotherm. The thermodynamic parameters values calculated clearly indicated that the adsorption process was feasible, spontaneous and endothermic in nature. These properties show that the pummelo peel has potential application in the removal of the uranium(VI) from the radioactive waste water.
\end{abstract}

Keywords Pummelo peel · Biosorption · Uranium

Q. Li · Y. Liu $(\bowtie) \cdot$ X. Cao $\cdot$ Z. Zhang $\cdot$ M. Hua

Key Laboratory Breeding Base of Nuclear Resources and Environment, East China Institute of Technology, Ministry of Education, Nanchang 330013,

People's Republic of China

e-mail: walton_liu@163.com

Q. Li $\cdot$ Y. Liu $\cdot$ X. Cao $\cdot$ C. Pang $\cdot$ Y. Wang $\cdot$ Z. Zhang ·

Y. Liu $\cdot$ M. Hua

Department of Chemistry, Biological and Materials Sciences,

East China Institute of Technology, Fuzhou 344000,

People's Republic of China

\section{Introduction}

With the rapid development of the global nuclear industry, there are more and more radioactive waste types and quantities. Uranium is a prominent element whose isotopes occur in various concentrations and oxidation states in radioactive waste. Uranium, like lead, cadmium, and arsenic, is deposited in the kidneys and cause irreparable damage to the main filtering mechanism of the body. Hence, its potential damage on human health and ecological environment is growing. Recently, removal of uranium from radioactive waste water has drawn increasing attentions. Several traditional methods including chemical clarification, precipitation, membrane filtration, and reverse osmosis are available for removing uranium from waste water. Biosorption has become a favorable method of choice, as it is economically and environmentally more viable [1].

Biomass possess a remarkable ability for taking up toxic and precious metals because cell walls of microbial biomass can offer electron donating functional groups or ligands such as carboxyl, hydroxyl, amide or phosphoryl groups for metal ion binding [2]. As a low-cost biosorbent, agricultural waste attracted people's attention in applying to treatment of heavy metals in wastewater because of several advantages: (1) rich sources and chemically stable; (2) a high surface area (porous); (3) high efficiency to treat low concentrations of heavy metals in wastewater; (4) easy to produce high concentrations of metal ion adsorption active groups; and (5) easy to make chemical modification.

Agricultural waste has unique chemical compositions, including hemicellulose, lignin, lipids, proteins, sugars, starch, etc., which contain different functional groups that will help remove heavy metal ions through the metal complex, especially the materials containing cellulose raw have high capacity on pronounced metal ion adsorption [3]. 
Studies have shown that a variety of agricultural waste can remove toxic heavy metal ions effectively, such as rice bran [4], rice husk [5], bark [6], peanut shells [7], coconut shell [8], wheat straw [9], waste tea leaves [10], bagasse [11], water hyacinth [12], coffee beans [13], a variety of plants, sawdust [14], etc. [15, 16].

Pummelo is a major fruit planting in many parts of the south of China. Pummelo peel accounted for 54-44\%, the quality of their internal white flocculent layer of the skin contains large amounts of cellulose. Discarding pummelo peel is usually not only resulted in waste, but polluted the environment. Currently, study of pummelo peel on how to extract the oil, pigment and pectin is primary. Saikaew and Kaewsarn [17] studied on simulated adsorption of cadmium ion by pummelo peel. The results showed that pummelo peel with the ability of adsorbed cadmium, and the absorption capacity can reach $21.83 \mathrm{mg} / \mathrm{g}$ at the $\mathrm{pH}$ of around 5 . However, to our knowledge, there is few report has been appeared for the uranium adsorption with pummelo peel.

In this context, we have studied the adsorption characteristics of uranium from aqueous solution onto pummelo peel. The influence of experimental conditions, such as $\mathrm{pH}$, initial metal ions concentration, biosorbent dosage and temperature on the biosorption features was investigated. The Langmuir and Freundlich were used to fit experimental data of the equilibrium isotherm. The biosorption rates were determined quantitatively and compared by pseudofirst and pseudo-second models. This study is a useful attempt to expand the recycling of agricultural waste, which not only saves cost, but also environmental friendly.

\section{Experimental}

Solutions and reagents

All of the chemical reagents used in the experiments were of analytical grades. For the preparation of a stock uranium(VI) solution, $1.1792 \mathrm{~g} \mathrm{U}_{3} \mathrm{O}_{8}$ was put into a $100 \mathrm{~mL}$ beaker, and $10 \mathrm{~mL}$ hydrochloric acid $(\rho=1.18 \mathrm{~g} / \mathrm{mL})$, $2 \mathrm{~mL} 30 \%$ hydrogen peroxide were added. The solution was heated until it was nearly dry and then $10 \mathrm{~mL}$ hydrochloric acid $(\rho=1.18 \mathrm{~g} / \mathrm{mL})$ was added. The solution was transferred to a $1,000 \mathrm{~mL}$ volumetric flask and diluted to the mark with distilled water to produce a uranium(VI) stock solution $(1 \mathrm{mg} / \mathrm{mL})$. The uranium solutions were prepared by diluting the stock solution to appropriate volumes depending upon the experimental requirements.

Preparation and characterization of biosorbent

The pummelo peel used in this study was obtained from a local fruit market of Jiangxi in China. The preparing procedure of biosorbent was described as follows. The collected biomass was rinsed with distilled water, then soaked in $0.1 \mathrm{M}$ sodium hydroxide for $4 \mathrm{~h}$, washed with distilled water to neutral, and then dried in an oven at $60{ }^{\circ} \mathrm{C}$ for $48 \mathrm{~h}$ at last. Dry biomass was crushed into granules and used for the adsorption studies. Fourier transform infrared (FTIR) spectra were obtained using a Nicolet 380 spectrometer (USA) using $\mathrm{KBr}$ pellets of samples.

\section{Adsorption studies}

The batch sorption of uranium studies was performed in a reciprocating thermostated air bath shaker. A concussion agitation speed of $200 \mathrm{rpm}$ was adopted for all experiments. In most of the experiments (except sorbent mass variation study), $0.01 \mathrm{~g}$ of sorbent was suspended in $100 \mathrm{~mL}$ solution of uranium. All experiments were performed in duplicates.

The concentration of uranium ions in solution was determined spectrophotometrically by Arsenazo-III method [18]. The adsorption amount $q(\mathrm{mg} / \mathrm{g})$ of uranium(VI) on adsorbent was calculated through the following equation:

$q=\frac{\left(c_{0}-c_{e}\right) V}{M}$

where $c_{0}$ and $c_{e}$ represent initial and equilibrium concentrations respectively $(\mu \mathrm{g} / \mathrm{mL}) . V$ is the volume of the solution in liter $(\mathrm{L})$ and $M$ is the mass of the adsorbent $(\mathrm{g})$.

Statistical evaluation of the kinetic and isotherm parameters

In this work, the kinetic and equilibrium models were fitted employing the linear fitting method using the software Microcal Origin 7.0.

\section{Results and discussion}

\section{Characterization of biosorbent}

Figure 1 shows the FT-IR spectrum of the pummelo peel before and after uranium biosorption. Before the adsorption, the peak appeared at $3,400 \mathrm{~cm}^{-1}$ which was assigned to $-\mathrm{OH}$ and $-\mathrm{NH}$ stretching vibration [19], indicating a large presence of hydroxyl and amino in pummelo peel. The peak observed at $2,921 \mathrm{~cm}^{-1}$ was assigned to saturated hydrocarbon $(\mathrm{C}-\mathrm{H})[20]$, while the peak at $1,619 \mathrm{~cm}^{-1}$ was assigned to a carbonyl band $(\mathrm{C}=\mathrm{O})$. The above facts shows that the pummelo peel contains carbonyl, which likely to come from acid or ester because of that skin contains large amounts of pectin and cellulose [21]. The peak observed at 


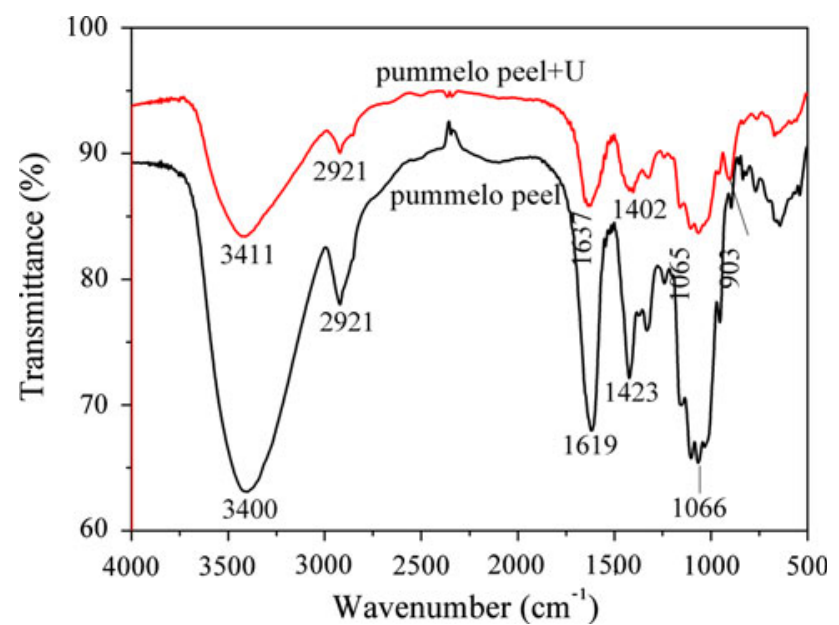

Fig. 1 FT-IR spectra for pummelo peel before and after uranium biosorption

$1,423 \mathrm{~cm}^{-1}$ was assigned to aromatic methyl, which is similar to the results of the literature [20].

After adsorption of uranium, the peak at $3,400 \mathrm{~cm}^{-1}$ weakened and shift to $3,411 \mathrm{~cm}^{-1}$, which indicated hydroxyl and amino groups participated in the binding of $\mathrm{U}(\mathrm{VI})$; the changes of the peaks at 1619 and $1,423 \mathrm{~cm}^{-1}$ indicated that aromatic methyl and carbonyl were present in the binding of $\mathrm{U}(\mathrm{VI}) ; 903 \mathrm{~cm}^{-1}$ appeared a new absorption peak for the uranyl ion stretching group. These results suggest that the hydroxyl, amino, carbonyl and aromatic methyl were involved in the process of adsorption uranium with the pummelo peel.

\section{Effect of $\mathrm{pH}$ on sorption}

Earlier studies on heavy metal biosorption have showed that $\mathrm{pH}$ is an important parameter affecting the biosorption process. It can influence the species of metal ions and ionization of surface functional groups [22]. The effect of $\mathrm{pH}$ on the adsorption of $\mathrm{U}(\mathrm{VI})$ onto the pummelo peel was carried out over the $\mathrm{pH}$ range $4.0-7.5$ using $50 \mu \mathrm{g} / \mathrm{mL}$ initial uranium concentration at $308 \mathrm{~K}$ and the results were displayed in Fig. 2. As shown in Fig. 2, the adsorption amount of the biosorbent increased as the $\mathrm{pH}$ increased from 3.5 to 5.5 and reached a maximum $270 \mathrm{mg} / \mathrm{g}$ at the $\mathrm{pH}$ of 5.5, which was used in rest of the further studies. The adsorption amount was decreased as the $\mathrm{pH}$ rise from 5.5 to 7.5. This phenomenon may be because pummelo peel contains carboxyl and hydroxyl groups, the $\mathrm{pH}$ affect the electrical properties and electric quantity of these groups. The low sorption at lower $\mathrm{pH}$ values could be attributed to $\mathrm{H}^{+}$competition with uranium binding sites [23]. At low $\mathrm{pH}$, the surface of the sorbent would be closely associated with protons $\left(\mathrm{H}_{3} \mathrm{O}^{+}\right)$which hindered the positively charged metal ions from reaching the binding sites of the sorbent.

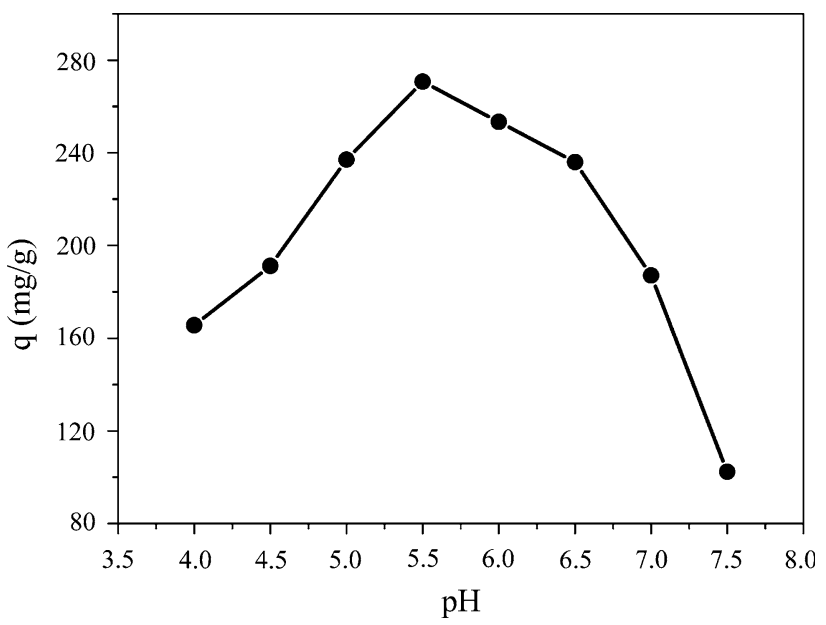

Fig. 2 Effect of pH on U(VI) adsorption by pummelo peel

The extent of adsorption decreased as $\mathrm{pH}$ continued to rise from 6.0 to 7.5, which could be explained by the increase in the dissolved carbonate concentration with increasing $\mathrm{pH}$. As dissolved carbonate and bicarbonate anions increased, they could compete adsorption sites with uranium(VI), thus resulting in a decrease in the adsorption amount continuously [24].

Effect of the amount of biosorbent on sorption

As it shown in Fig. 3, the adsorption capacity of uranium onto pummelo peel increased with the increase of the amount of pummelo peel. This is because the greater amount of pummelo peel can provide more surface functional groups and surface sites, which increased the adsorption capacity. When the adsorbent dosage is $0.05 \mathrm{~g}$, and the concentration of uranium is $30 \mu \mathrm{g} / \mathrm{mL}$, the removal rate can reach $97 \%$ or more. When the adsorbent dosage is more than $0.03 \mathrm{~g}$, the removal rate increases slowly and then tends to remain unchanged,

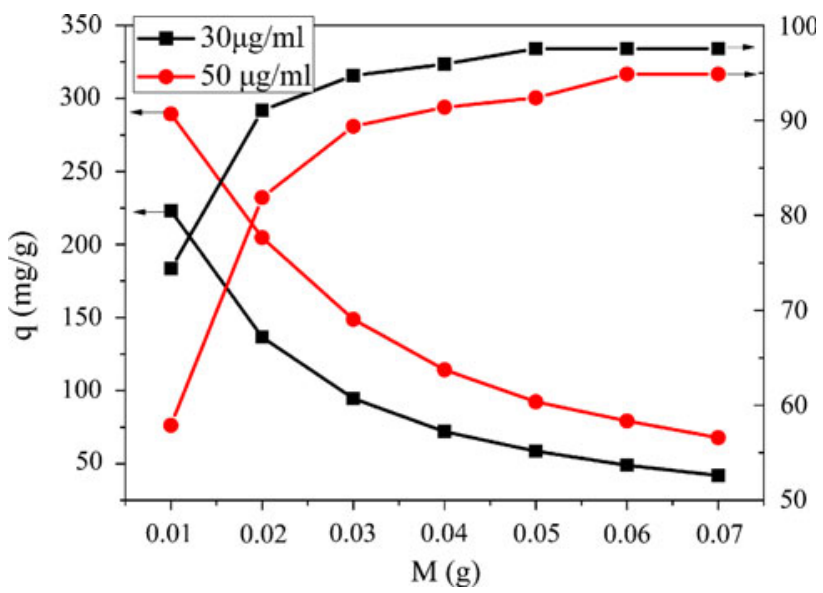

Fig. 3 Effect of sorbent dose on the sorption of U(VI) onto pummelo peel 


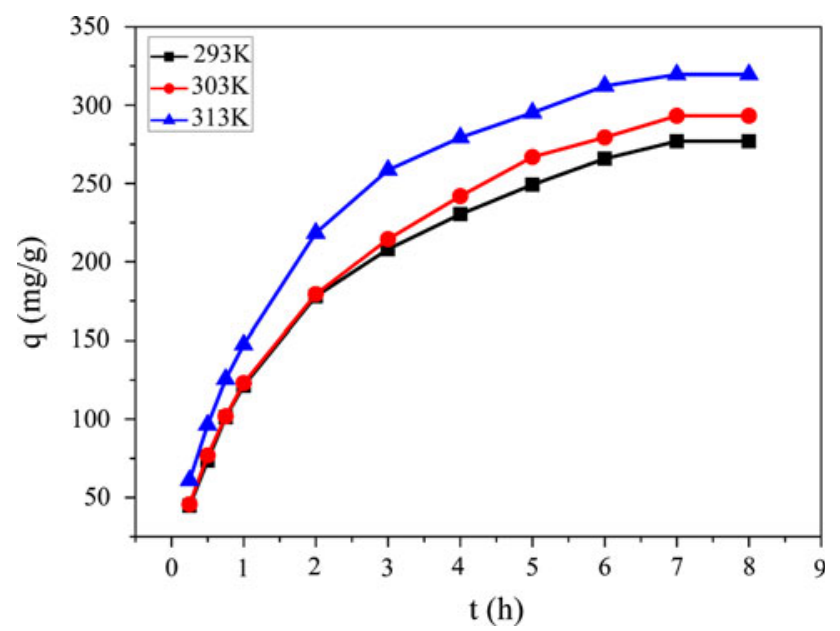

Fig. 4 Effect of contact time on U(VI) adsorption by pummelo peel

which can be explained by that some active adsorption sites can not be exposed due to the skin aggregation or too much uranium in the remaining solution. Figure. 3 also shows that adsorption capacity of uranium on pummelo peel decreases while the amount of pummelo peel continues increasing. This is because the greater the amount of pummelo peel can provide more metal ion adsorption sites, so that pummelo peel binding sites can not be fully utilized, resulting in falling adsorption capacity of per unit mass.

\section{Sorption kinetics}

Adsorption time is another factor affecting the adsorption of heavy metals. Figure 4 shows that adsorption time effect adsorption capacity greatly in the early adsorption. Therefore, at the temperature 293, 303 and $313 \mathrm{~K}$ the best times to reach adsorption equilibrium are $7 \mathrm{~h}$. Adsorption rate of uranium is fast at the start, followed the adsorption process has become slow. This is because pummelo peel absorption of uranium is not saturated in a short time, the adsorption rate is higher; then the pummelo peel surface adsorbed a lot of uranium, resulting in the adsorption activity site that can be used has reduced and increasing the difficulty for interface elements to get into the micro-hole.

In order to characterize the biosorption kinetics, several kinetic models were applied to the experimental data. Pseudofirst-order and pseudo-second-order kinetic equations were

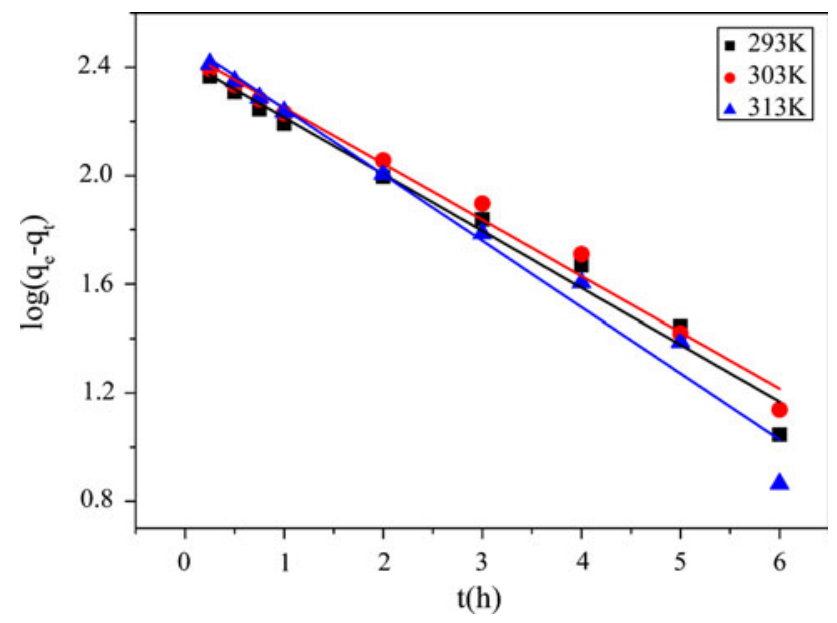

Fig. 5 Pseudo-first-order kinetic plot for the adsorption of U(VI) onto pummelo peel

applied to describe the kinetic characteristic of uranium(VI) onto the pummelo peel.

The integrated linear form of Eq. (2) can be expressed as: [19]

$\log \left(q_{e}-q_{t}\right)=\log q_{e}-k_{1} t / 2.303$

Where $q_{t} q_{e}\left(\mathrm{mg} \mathrm{g}^{-1}\right)$ and $k_{l}\left(\mathrm{~h}^{-1}\right)$ are the amounts biosorbed at time $t$, equilibrium and the pseudo-first-order adsorption rate constant of the biosorption process, respectively.

Using Eq. (2), a linear plot of $\log \left(q_{e}-q_{t}\right)$ versus $t$ was plotted (Fig. 5). The rate constants $k_{1}$ calculated equilibrium biosorption capacities $q_{e, \text { cal }}$ and correlation coefficient $\left(R^{2}\right)$ at different temperatures obtained from the slopes and intercepts of the plots are given in Table 1. It was found that the correlation coefficients for the pseudo-first-order kinetic model were higher than 0.97 for all temperatures, moreover, the $q_{e, \text { cal }}$ values for the pseudo-first-order kinetic model also agree with the experimental data. These results suggest that the kinetic adsorption can be described by the pseudo-first-order kinetics very well.

The pseudo-second-order kinetic model has been considered to be the most appropriate in the last years. The pseudo-second-order equation can be expressed following Eq. (3)

$t / q_{t}=1 / k_{2} q_{e}^{2}+t / q_{e}$

Table 1 The kinetic parameters of pummelo peel

\begin{tabular}{|c|c|c|c|c|c|c|}
\hline \multirow[t]{2}{*}{ Temperature (K) } & \multicolumn{3}{|c|}{ Pseudo-first-order model } & \multicolumn{3}{|c|}{ Pseudo-second-order model } \\
\hline & $k_{1}\left(\mathrm{~h}^{-1}\right)$ & $q_{e, \mathrm{cal}}\left(\mathrm{mg} \mathrm{g}^{-1}\right)$ & $R^{2}$ & $k_{2}\left(\mathrm{~g} \mathrm{mg}^{-1} \mathrm{~h}^{-1}\right)$ & $q_{e, \text { cal }}\left(\mathrm{mg} \mathrm{g}^{-1}\right)$ & $R^{2}$ \\
\hline 293 & 0.4823 & 265.3 & 0.9790 & 0.001623 & 341.3 & 0.9986 \\
\hline 303 & 0.4769 & 286.8 & 0.9871 & 0.001391 & 367.6 & 0.9977 \\
\hline 313 & 0.5619 & 309.8 & 0.9737 & 0.001765 & 383.1 & 0.9989 \\
\hline
\end{tabular}




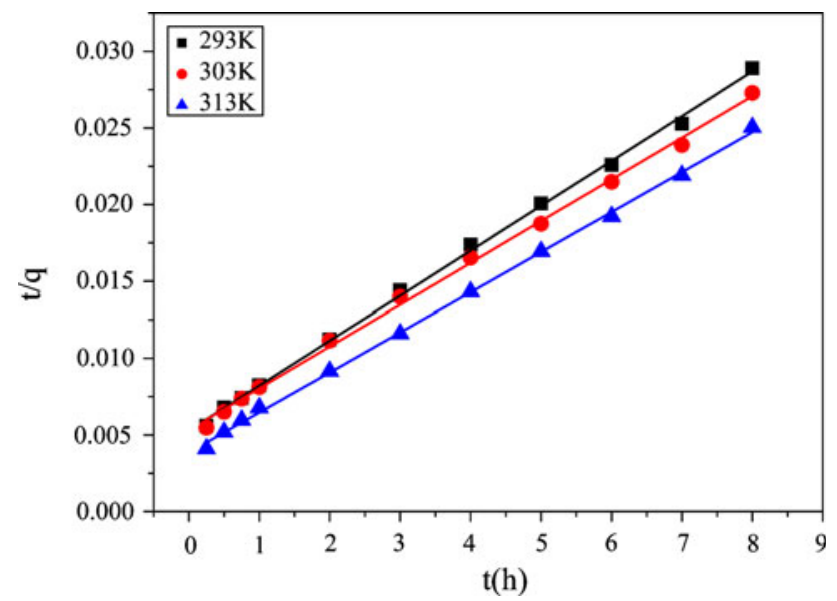

Fig. 6 Pseudo-second-order kinetic plot for the adsorption of U(VI) onto pummelo peel

where $k_{2}\left(\mathrm{~g} \mathrm{mg}^{-1} \mathrm{~h}^{-1}\right)$ is the pseudo-second-order rate constant. Using Eq. (3), linear plot of $\log \left(q_{e}-q_{t}\right)$ versus $t$ was plotted (Fig. 6). The rate constants $k_{2}$ and calculated equilibrium biosorption capacities $\mathrm{q}_{e, \text { cal }}$ obtained from the intercepts and slopes of the plots are given in Table 1. Though the correlation coefficient values $R^{2}$ were higher than 0.99 for all temperatures, the $q_{e, \text { cal }}$ calculated values and the experimental values $q_{e, \exp }$, are not close, showing that the biosorption kinetics for the entire process did not follow the pseudo-second-order model. These results suggest that the kinetic adsorption can be described by the pseudo-first-order kinetics very well.

\section{Biosorption isotherm}

The adsorption isotherm was carried out at different temperatures 293, 303 and $313 \mathrm{~K}$ with initial concentration of uranium(VI) varying from 30 to $80 \mu \mathrm{g} / \mathrm{mL}$. To ensure full equilibration, a shaking time of $7 \mathrm{~h}$ was used for all concentrations of uranium(VI) in this study. As shown in Fig. 7, the biosorption capacities of pummelo peel for uranium(VI) is increasing with increasing temperature from 293 to $313 \mathrm{~K}$. This could be due to higher probability of collision between metal ions and the adsorbent surface and stronger driving force, which lessened the mass transfer resistance. Since the biosorption increased with temperature, therefore, the system is endothermic.

Adsorption isotherms describe how solute interacts with the adsorbent under equilibrium conditions, and so, is one of the most important data to understand the mechanism of the adsorption systems. Two biosorption isotherm models, namely Langmuir and Freundlich isotherm models were used to fit the biosorption experimental data in this study. The Langmuir model is based on assumptions of adsorption homogeneity such as equally available adsorption sites,

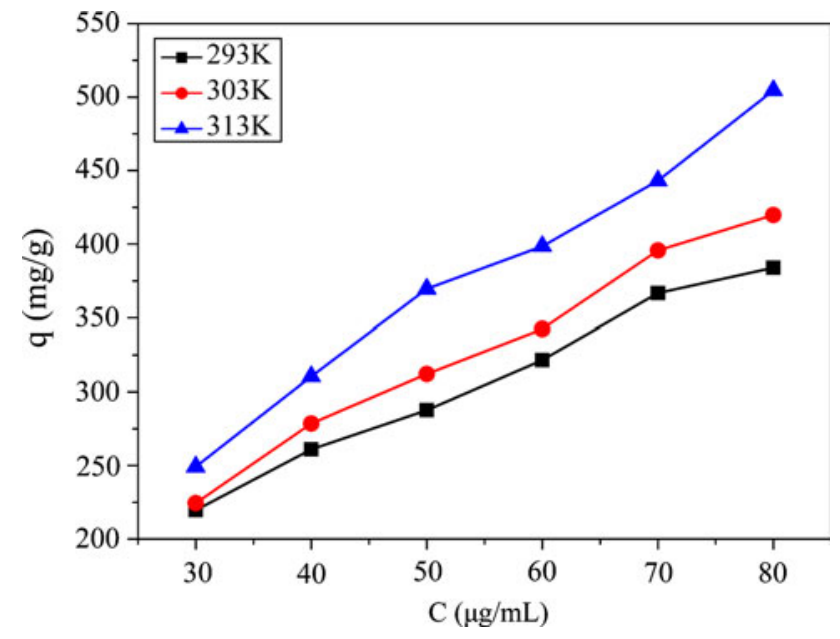

Fig. 7 Effect of initial uranium concentration on U(VI) adsorption by pummelo peel

monolayer surface coverage, and no interaction between adsorbed species [25] and can be described by the linearized form [26].

$C_{e} / q_{e}=1 / Q_{0} K_{L}+C_{e} / Q_{0}$

where $q_{e}$ is the amount of solute per unit weight of sorbent $(\mathrm{mg} / \mathrm{g}), C_{e}$ is the equilibrium concentration $(\mu \mathrm{g} / \mathrm{mL}), Q_{0}$ is the saturated monolayer sorption capacity $(\mathrm{mg} / \mathrm{g})$ and $K_{L}$ is the Langmuir isotherm constant that relates to the energy of adsorption (L/mg).

The essential characteristics of the Langmuir isotherm can be expressed in terms of a dimensionless constant separation factor or equilibrium parameter $R_{L}$, [27] which is defined as:

$R_{L}=1 /\left(1+K_{L} C_{0}\right)$

where $K_{L}$ is Langmuir constant $(\mathrm{L} / \mathrm{mg}), C_{0}$ is the initial concentration $(\mu \mathrm{g} / \mathrm{mL})$. The value of $R_{L}$ indicates the type of isotherm to be irreversible $\left(R_{L}=0\right)$, favorable $\left(0<R_{L}<1\right)$, linear $\left(R_{L}=1\right)$ or unfavorable $\left(R_{L}>1\right)$.

The Freundlich model can be applied to nonideal sorption on heterogeneous surfaces as well as multilayer sorption [28]. The empirical Freundlich equation [29] can also be transformed into linear form:

$\log q_{e}=\log K_{f}+\log C_{e} / n$

where $q_{e}$ is the amount of solute sorbed per unit weight of sorbent $(\mathrm{mg} / \mathrm{g}), C_{e}$ is the equilibrium concentration $(\mu \mathrm{g} /$ $\mathrm{mL}), K_{f}$ and $n$ are the Freundlich constants related to the adsorption amount and adsorption intensity of the sorbent, respectively.

The linearized form of Langmuir and Freundlich adsorption isotherms obtained at 293, 303 and $313 \mathrm{~K}$ were presented in Figs. 8 and 9, respectively, whereas the adsorption constants evaluated from the isotherms with the 


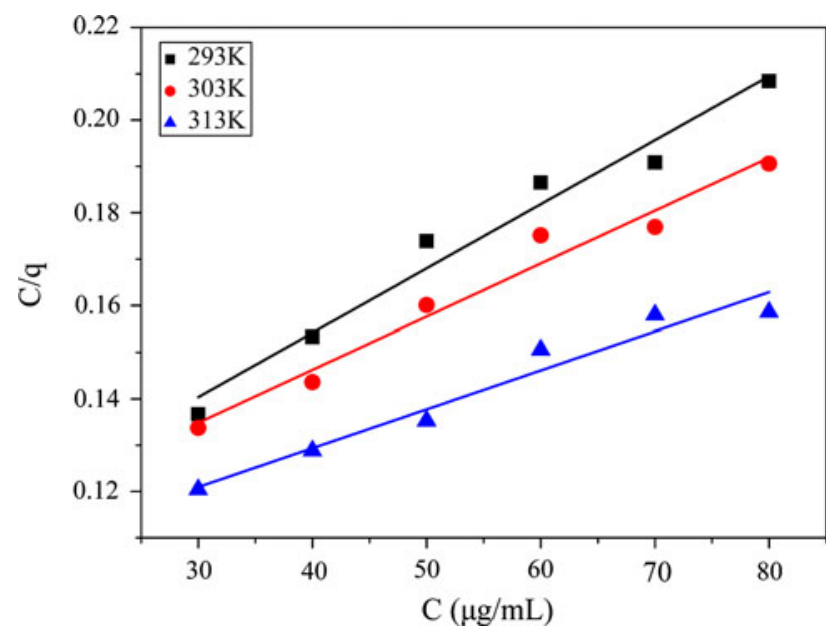

Fig. 8 Langmuir isotherm of sorption U(VI) on pummelo peel

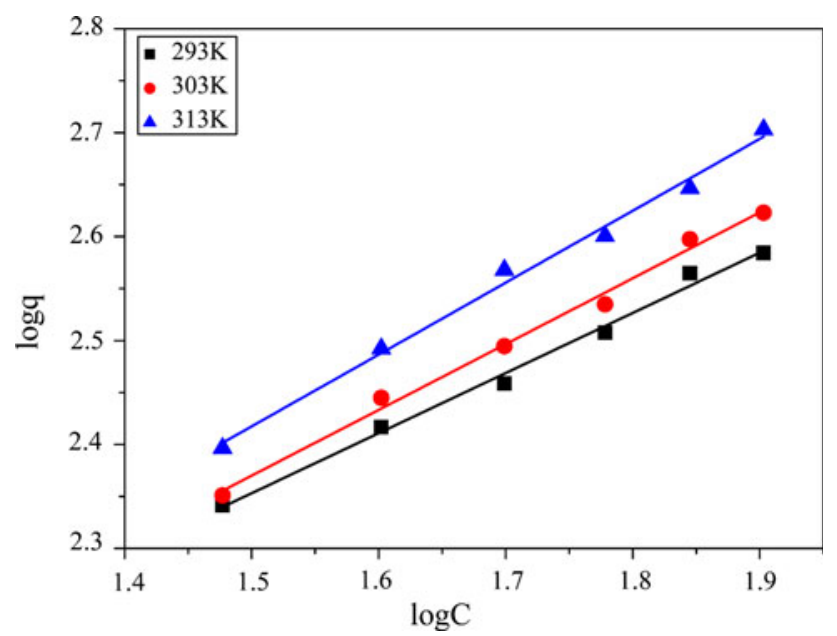

Fig. 9 Freundlich isotherm of sorption U(VI) on pummelo peel

correlation coefficients were given in Table 2. The results show that Langmuir and Freundlich isotherm models fitted well for the adsorption studies $\left(R^{2}>0.94\right)$; however, Freundlich isotherm had a better fitting model than Langmuir isotherm $\left(R^{2}>0.99\right)$. Langmuir constant, $Q_{0}$, represents the maximum monolayer adsorption amount of the biosorbent. The values are $724.6,877.2$ and $1192.321 \mathrm{mg} / \mathrm{g}$ at 293,303 and $313 \mathrm{~K}$, respectively. It was also found that the $R_{L}$ values calculated are in the range of $0<R_{L}<1$, which indicates that the adsorption of $\mathrm{U}(\mathrm{VI})$ on the pummelo peel is favorable. As seen from Table 2, the values of the
Freundlich constant ( $n$ and $K_{f}$ ) showed rapid uptake of the uranium from solution with high adsorptive capacity of pummelo peel.

Thermodynamic parameters

Thermodynamic behavior of the biosorption of pummelo peel biomasses is evaluated by the thermodynamic parameters including the change of Gibbs free energy $(\Delta G)$, enthalpy $(\Delta H)$ and entropy $(\Delta S)$. The thermodynamic data at various temperatures were calculated using the following equations [30].

$K_{d}=\left(C_{0}-C_{e}\right) V /\left(C_{e} m\right)$

Where the distribution coefficient, $K_{d}(\mathrm{~mL} / \mathrm{g})$, was used to compute the apparent thermodynamic parameters, $C_{0}$ and $C_{e}$ are the concentration of the initial solution and equilibrium, $V$ is the volume of the solution $(\mathrm{mL})$ and $m$ is the weight of the sorbent $(\mathrm{g})$.

The values of $\Delta H^{\circ}$ and $\Delta S^{\circ}$ were calculated from the slope and intercept of the linear variation of $\ln K_{d}$ with reciprocal temperature (Fig. 10) by the equation:

$\operatorname{In} K_{d}=\Delta S^{\circ} / R-\Delta H^{\circ} / R T$

where $K_{d}$ is distribution coefficient, $R$ is the gas constant $(8.314 \mathrm{~J} / \mathrm{mol} \cdot \mathrm{K})$ and $T$ is the absolute temperature in Kelvin (K). The change of Gibbs free energy, $\Delta G^{\circ}$, can be calculated by:

$\Delta G^{\circ}=\Delta H^{\circ}-T \Delta S^{\circ}$

The values of thermodynamic parameters for the sorption of U(VI) at different temperature were given in Table 3 . The values of $\Delta G^{\circ}$ were found to be -23.17 , -24.47 and $-25.77 \mathrm{~kJ} / \mathrm{mol}$ at 293,303 and $313 \mathrm{~K}$, respectively. The negative values of $\Delta G^{\circ}$ at different temperatures confirm the feasibility and spontaneous nature of adsorption process. Further, the decrease in the values of $\Delta \mathrm{G}^{\circ}$ with the increasing temperature indicates that higher temperature favors the sorption process. The value of $\Delta H^{\circ}$ $14.95 \mathrm{~kJ} / \mathrm{mol}$ suggests that the adsorption of uranium (VI) is endothermic and hydrogen bonding process [31]. The positive value of $\Delta S^{\circ}$ reflects the affinity of the biosorbent for uranium(VI) and confirms the increased randomness at the solid solution interface during adsorption.
Table 2 Isotherm parameters for the adsorption of $\mathrm{U}(\mathrm{VI})$ on pummelo peel at different temperatures

\begin{tabular}{llllllll}
\hline Temperature (K) & \multicolumn{2}{l}{ Langmuir isotherm } & & \multicolumn{3}{l}{ Freundlich isotherm } \\
\cline { 2 - 3 } & $K_{L}\left(\mathrm{~L} \mathrm{mg}^{-1}\right)$ & $Q_{0}\left(\mathrm{mg} \mathrm{g}^{-1}\right)$ & $R^{2}$ & & $K_{f}$ & $n$ & $R^{2}$ \\
\hline 293 & 0.01395 & 724.6 & 0.9654 & & 30.5774 & 1.7289 & 0.9913 \\
303 & 0.01133 & 877.2 & 0.9653 & & 26.3330 & 1.5798 & 0.9917 \\
313 & 0.00876 & 1192.3 & 0.9446 & & 24.0049 & 1.4463 & 0.9911 \\
\hline
\end{tabular}




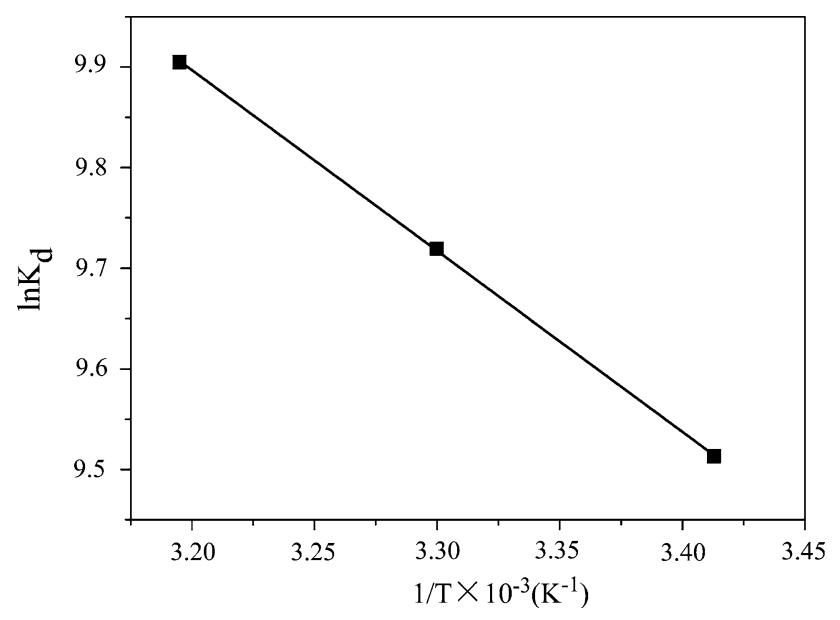

Fig. 10 The diagram of $\ln K_{\mathrm{d}^{-}}-1 T$ of pummelo peel

Table 3 Thermodynamic parameters for the sorption $\mathrm{U}(\mathrm{VI})$ on pummelo peel

\begin{tabular}{lllll}
\hline$\Delta H^{\circ}$ & $\begin{array}{l}\Delta S^{\circ} \\
\left(\mathrm{kJ} \mathrm{mol}^{-1}\right)\end{array}$ & $\left(\mathrm{J} \mathrm{mol}^{-1} \mathrm{~K}^{-1}\right)$ & \multicolumn{4}{l}{$\Delta G^{\circ}\left(\mathrm{kJ} \mathrm{mol}^{-1}\right)$} \\
\cline { 3 - 5 } & $293 \mathrm{~K}$ & $303 \mathrm{~K}$ & $313 \mathrm{k}$ \\
\hline 14.95 & 130.11 & -23.17 & -24.47 & -25.77 \\
\hline
\end{tabular}

\section{Conclusions}

The present study focuses on the biosorption of uranium from aqueous solution using the pummelo peel as a lowcost biosorbent. The biosorption characteristics have been examined at different temperature, initial concentration, and contact time. The maximum capacity was observed at the $\mathrm{pH}$ value of 5.5 and at $7 \mathrm{~h}$. Kinetic studies on sorption of uranium by the biosorbent revealed that the experimental data showed better fit to the pseudo-first-order kinetic model. The experimental data were evaluated by Langmuir, Freundlich isotherms. Equilibrium data were well fitted to Freundlich isotherm model. The thermodynamic calculations indicated the feasibility, endothermic and spontaneous nature of the biosorption process.

Acknowledgments We gratefully acknowledge the financial support provided by National Natural Science Foundation of China (Grant no. 21101024), Key Project of Chinese Ministry of Education (Grant no. 211086), Natural Science Foundation of Jiangxi Provincial (Grant no. 20114BAB203002) and China Postdoctoral Science Foundation (Grant no. 20110490857). Natural Science Foundation of Jiangxi Province (no. 2010GQH0015), the Sci. and Tech. Project of Jiangxi Provincial Department of Education (no. GJJ11139) and the Open Project Foundation of the Key Laboratory of Radioactive Geology and Exploration Technology Fundamental Science for National Defense, East China Institute of Technology, China (2010RGET08).

\section{References}

1. Khambhaty Y, Mody K, Basha S, Jha B (2009) Chem Eng J 1453:489

2. Yang J, Volesky B (1999) Water Res 3315:3357

3. Hashem A, Akasha R, Ghith A, Hussein D (2007) Energy Edu Sci Technol 19:69

4. Singh K, Rastogi R, Hasan S (2005) J Colloid Interface Sci 2901:61

5. Ajmal M, Ali Khan Rao R, Anwar S, Ahmad J, Ahmad R (2003) Bioresour Technol 862:147

6. Vazquez G, Antorrena G, Gonzalez J, Doval M (1994) Bioresour Technol 483:251

7. Romero LC, Bonomo A, Gonzo EE (2004) Adsorpt Sci Technol 223:237

8. Pino GH, Souza de Mesquita LM, Torem ML, Saavedra Pinto GA (2006) Miner Eng 195:380

9. Chun L, Hongzhang C, Zuohu L (2004) Process Biochem 395:541

10. Ahluwalia S, Goyal D (2005) Eng Life Sci 52:158

11. Srivastava VC, Mall ID, Mishra IM (2006) Chem Eng J 1171:79

12. Kelley C, Mielke RE, Dimaquibo D, Curtis AJ, Dewitt JG (1999) Environ Sci Technol 339:1439

13. Kaikake K, Hoaki K, Sunada H, Dhakal RP, Baba Y (2007) Bioresour Technol 9815:2787

14. Bulut Y, Tez Z (2007) J Environ Sci 192:160

15. Marshall WE, Champagne ET (1995) J Environ Sci Health A 302:241

16. Mohan D, Pittman CU Jr (2006) J Hazard Mater 1372:762

17. Saikaew W, Kaewsarn P (2009) Songklanakarin J Sci Technol 315:547

18. Bhatti TM, Mateen A, Amin M, Malik KA, Khalid AM (1991) J Chem Technol Biotechnol 523:331

19. Bayramoğlu G, Çelik G, Arica MY (2006) J Hazard Mater 1362:345

20. Guo X, Zhang S, Shan X-q (2008) J Hazard Mater 1511:134

21. Pavan FA, Lima EC, Dias SLP, Mazzocato AC (2008) J Hazard Mater 1503:703

22. Gupta VK, Rastogi A (2008) Colloids Surf B Biointerfaces 642:170

23. Parab H, Joshi S, Shenoy N, Verma R, Lali A, Sudersanan M (2005) Bioresour Technol 9611:1241

24. Barnett M, Jardine P, Brooks S, Selim H (2000) Soil Sci Soc Am J 643:908

25. Bayramoğlu G (2003) J Appl Polym Sci 887:1843

26. Langmuir I (1918) J Am Chem Soc 409:1361

27. Hall KR, Eagleton LC, Acrivos A, Vermeulen T (1966) Ind Eng Chem Fundam 52:212

28. Gerente C, Lee V, Cloirec PL, McKay G (2007) Crit Rev Environ Sci Technol 371:41

29. Freundlich H (1906) Z Phys Chem 57:385-470

30. Kilislioglu A, Bilgin B (2003) Appl Radiat Isot 582:155

31. Hassett JJ, Banwart WL (1989) Sorption of nonpolar organics by soils and sediments. In: Proceedings of a symposium of the Soil Science Society of America and the American Society of Agronomy, Atlanta, Georgia, November 30-December 1, 1987. SSSA Special Publication No. 22. Soil Science Society of America, Inc., Madison, WI. pp 30-45, 11 fig, 17 ref 